\title{
Life-Course-Persistent Antisocial Behavior
}

\section{Robert Eme*}

Department of Clinical Psychology, Argosy University, Illinois, Schaumburg, USA.

\begin{abstract}
The article reviewed the status of the Life Course Persistent category of antisocial behavior some two decades plus from its original formulation as well as the finding from the landmark Dunedin longitudinal study of antisocial behavior that this category is comprised almost entirely of males. The importance of this category for forensic psychology is the robust and remarkable finding that the small group of individuals (5-10\%) who tend to cluster in this category are responsible for over half of all crimes in the United States and other developed countries, and an even greater proportion of violent crimes.
\end{abstract}

Keywords: Persistent; Antisocial; Behavior; Conduct disorder; Psychiatric disorder

\section{Introduction}

Early starting life course persistent antisocial behavior of males is arguably the most important pediatric mental health problem [1]. This category of antisocial behavior has its origins in Moffitt's developmental theory of conduct disorder [2], which proposed a dual taxonomy of lifecourse-persistent (LCP) and adolescent-limited (AL) antisocial behavior as a way of explaining marked individual differences in the stability of delinquency. The central tenet of the initial formulation of Moffitt's theory was that LCP and AL individuals comprise distinct subgroups with unique developmental trajectories and etiologies [2,3]. The LCP subgroup was relatively small (5\%-10\%), almost exclusively male [4], and exhibited antisocial behavior beginning in childhood, which tended to persist into adulthood. The stability of this behavior suggested that LCP delinquency had roots early in life, and was likely to be caused by inherited or acquired neurobiological and neuropsychological variation that occurred more frequently among males, thereby explaining the observed sex difference in prevalence [4]. The AL subtype referred to a much larger group whose antisocial behavior was limited largely to adolescence. Their delinquent behavior was hypothesized to be caused by a maturity gap (such as a desire for autonomy), not neurobiological or neuropsychological variation, which prompted youth to engage temporarily in social mimicry of LCP antisocial behaviors via peer reinforcement. As these youth matured, they outgrew their motivation for delinquency. Moffitt concluded that to understand the etiology of severe, persistent, antisocial behavior, researchers must focus on LCP cases, and by implication biological vulnerabilities underlying their condition. The importance of this seminal article on categories of antisocial behaviors is illustrated by the fact at the time of writing this review it has been cited over 7000 times by others according to Google Scholar, making it one of the most highly cited papers in psychology. The theory informed the distinction between childhood-onset and adolescent-onset forms of conduct disorder listed in the DSM-IV and DSM-5. In addition, the article triggered a cataract of research on types of criminal offending [5]. In short, Moffitt authored what is one of the most influential of all developmental theories of antisocial behavior [6].

Since the 1993 article, two other categories of antisocial behavior have been identified: childhood limited and adult onset antisocial behavior. The childhood limited group refers to children who despite exhibiting extreme and pervasive antisocial behavior do not continue to exhibit such high levels of antisocial behavior into adolescence or adulthood, though they may engage in less serious antisocial behavior and exhibit other forms of maladjustment [7-9]. Although there are too few studies to date to yield any reliable findings on the characteristics of the members of this group, there is some preliminary evidence that these children in contrast to the LCP group are less subject to harsh parenting, less likely to have a family history of psychiatric disorder, and possess higher levels of social and linguistic competence [7]. In the adult onset group, there is some evidence that high nervousness and few friends in adolescence may have deferred the onset of these individual's offending until early adulthood [5].

The purpose of this mini-review will be to examine the status of the LCP category some two decades plus from its original formulation as well as the finding from the landmark Dunedin longitudinal study of antisocial behavior that this category is comprised almost entirely of males [10]. The reason for the focus on this category is the robust and remarkable finding that the small group of individuals (5-10\%) who tend to cluster in the LCP category are responsible for over half of all crimes in the United States and other developed countries, and an even greater proportion of violent crimes [5,11-14]. For example, in the classic study Delinquency in a Birth Cohort, out of the nearly 10,000 boys in a Philadelphia birth cohort, just $6 \%$ committed over $50 \%$ of the delinquency in the entire cohort, including $71 \%$ of the murders, $73 \%$ of the rapes, and $69 \%$ of the aggravated assaults [14]. The behavioral and collateral consequences of this relatively small group are profound and pervasive, resulting in the United States in billions of dollars in terms of justice system, victimization, mental health, and associated costs [14]. The mini review will, of necessity, given the voluminous literature and given the 'mini' nature of the review, draw heavily on analyzing and synthesizing several existing reviews.

\section{Early Starting Life-Course Antisocial Behavior}

The two decades plus of research since 1993 has provided overwhelming support for a category of a small group of individuals who engage in early starting, persistent antisocial behavior and who tend to have more risk factors for antisocial behavior than any other

*Corresponding author: Robert Eme, Department of Clinical Psychology, Argosy University, Illinois, Schaumburg, USA, Tel: 8479694949; E-mail: reme@argosy.edu

Received December 23, 2015; Accepted January 04, 2016; Published January 12,2016

Citation: Eme R (2016) Radial Life-Course-Persistent Antisocial Behavior. J Foren Psy 1: 101. doi: 10.4172/2475-319X.1000101

Copyright: (c) 2016 Eme R. This is an open-access article distributed under the terms of the Creative Commons Attribution License, which permits unrestricted use, distribution, and reproduction in any medium, provided the original author and source are credited. 
group [3,7,8,15-18]. The trajectory of offending of individuals in this category has been concisely summarized by Le Blanc [18]. Although they typically start offending in childhood around age 8, a subset of early-starting youth engaging in significant antisocial behavior can be identified during early childhood beginning around age 3 [19]. They peak in their offending in late adolescence, maintain a high level of offending during the twenties, and begin declining in their offending in the thirties. The trajectory is characterized by high variety, frequency, and seriousness of offending. Thus the central tenet of Moffitt's LCP category has been resounding affirmed and "It is axiomatic that criminal career extremity is inversely related to onset" [20]. However, there has been a growing consensus that the theory is also in need of two major revisions that challenged the "uniqueness" of the etiology and trajectory of LCP as compared to AL $[16,21]$.

The first revision is anchored in the cardinal principle of developmental psychopathology that virtually all childhood conditions and disorders are best understood in dimensional rather than categorical terms [22]. Namely, most forms of psychopathology reflect an extreme expression on a continuously distributed dimension rather than expression of membership in a distinct category in which the individual either does or does not have a disorder. Hence, it comes as no great surprise that two recent, comprehensive reviews have concluded that the distinction between the LCP and AL groups reflects quantitative/dimensional differences not categorical/qualitative differences $[16,21]$. Thus, other than age of onset, what distinguish juveniles in the LCP group from juveniles in the AL group are a more extreme form of antisocial behavior and a higher level of risk factors rather than qualitatively different characteristics or risk factors that are unique to LCP. For example, with regard to characteristics, what most distinguish LCP from AL are higher levels of aggression and a more extensive criminal history [21]. With regard to risk factors, the single most important finding, since it challenges the linchpin of Moffitt's theory of a qualitative/categorical difference between LCP and AL, is that neurobiological factors play an important causal role not only in LCP but also AL. Therefore, LCP can no longer be considered to be a qualitatively distinct disorder because of the unique role played by neuropsychological and neurobiological factors [16]. However, the elimination of this qualitative distinction between LCP and AL in neurobiological factors should not be allowed to obscure two important quantitative differences. First, it appears that LCP juveniles tend to have more severe neuropsychological or neurological impairments than $\mathrm{AL}$ juveniles [16]. Second, there is a relatively large difference between LCP and $\mathrm{AL}$ juveniles on the physiological factor that is commonly accepted as best-replicated and most robust risk factor for the development of antisocial behavior - low resting heart rate $[21,23,24]$. Low resting heart rate is hypothesized to increase risk for antisocial behavior through the following mechanisms. Low resting heart rate is a marker for low autonomic hypo arousal which in turn is thought to index low fear and anxiety. Lower levels of fear and anxiety may result in increased insensitivity to punishment, reduced anxiety and guilt associated with wrong-doing, and thus increase the risk for engaging in antisocial behavior.

The second revision comes from findings that challenge Moffitt's theory that AL has a "unique" trajectory in contrast to LCP in that AL's antisocial behavior was hypothesized to be "limited" to adolescence and thus remitted as the individual entered adulthood. However, it is now clear that many individuals with adolescent-onset antisocial behavior continue their antisocial behavior into adulthood [16], though the level of AL's continuing antisocial behavior is much less than that of LCP's. For example, the Dunedin study found that official (court) convictions for violence for males at age 32, which tend to reflect more serious kinds of violence than self-reported violence [7], were much more frequent for LCP than AL individuals: $33 \%$ vs. $8 \%$ [25]. Indeed, the LCP individuals accounted for $72 \%$ of the months spend in jail for the entire male cohort in the study [25].

\section{LCP and Maleness}

As previously mentioned, Moffitt and colleagues reported a very large sex difference based in the Dunedin Multidisciplinary Health and Development study, in which LCP characterized $10 \%$ of males and $1 \%$ of females (10:1 male/female sex ratio). This finding prompted Moffitt [26] to describe LCP as "almost exclusively male." Subsequent findings from related research reporting sex ratios ranging from $3: 1$ to 15:1 are broadly consistent with this finding; and thus it is commonly accepted that female LCP is rare $[16,26]$. Divergence in reported sex ratios may result primarily from measurement differences, which result in variations in the severity of the antisocial behavior criteria used to designate an individual as LCP. Moffitt used criteria that identified the most severely antisocial individuals, who are almost exclusively male. Less stringent criteria identify less severely antisocial individuals, with correspondingly lower sex ratios (personal communications with $\mathrm{T}$. Moffitt, April 17, 2013, and C. Odgers, April 9, 10, 2013). The rarity of female LCP receives strong support from research in the criminological literature on career criminality (the criminological equivalent of LCP), which reports male/female ratios ranging from 9:1 to 12:1 [27].

The robustness of this sex difference receives additional impressive support from findings of a similarly large sex difference in two other domains closely related to LCP — physical aggression and violence. Physical aggression is more common in males at all ages and across all cultures. It is most evident in reports from self, peers, and teachers of real-world, severe aggression, and in male-on-male aggression [2833]. Effect sizes generally range from medium (teacher report) to large (peer) for children $[29,34,35]$, and emerge early in life [28-30]. Such differences are stable through childhood, adolescence, and adulthood $[31,36]$. By adolescence, approximately $5 \%$ of males engage in chronic physical aggression, whereas female cases are rare [32,33]. For example, in a large general population of 14 to 17 -year-old adolescents $(n=1165)$, aggressive conduct disorder was found to be $13 \%$ for males but only $0.4 \%$ in females [37].

Violence, which can be defined as behavior that is intended to cause physical and psychological injury, including homicide, assault, robbery, and rape, represents the most extreme form of physical aggression [38]. A sex difference in prevalence of violence typically emerges in middle or late adolescence [39]. According to Tremblay [32], "Physical violence by females during adolescence is generally so rare that modeling their developmental trajectories fails." Similarly, Pinker notes, "The one great universal in the study of violence is that most of it is committed by fifteen-to-thirty-year-old men." Indeed, violence, in its most extreme forms of same-sex homicide and war, is virtually an exclusive male phenomenon [40,41].

\section{Conclusion}

Research since Moffitt's landmark 1993 article has unequivocally established the population/epidemiological validity of an LCP type of antisocial behavior. It has also confirmed that LCP is overwhelming male with females rarely showing LCP. However, subsequent research has challenged the validity of Moffitt's initial formulation that LCP is "unique" in etiology and trajectory in relation to AL. Thus LCP is best understood as representing a much more severe form of antisocial 
behavior compared to $\mathrm{AL}$ rather than qualitatively distinct category of antisocial behavior.

Lastly, perhaps the most important impact of the LCP model on antisocial theory is that it is now commonly accepted that if prevention of antisocial behavior is to be most effective, it must "begin at the beginning" [42], starting in preschool if not earlier, i.e., pregnancy $[9,43]$. Unfortunately, implementation of and evidence for the effectiveness of preventative interventions for juvenile antisocial behavior is scant, as it is for preventative intervention of juvenile mental health problems in general [44]. For example, with regard to antisocial behavior, the best way to evaluate the effectiveness of preventative interventions would be within the context of a prospective longitudinal study of preschool children at high risk for antisocial behavior using a randomized design [45]. No such large scale study has ever been carried out [45].

\section{References}

1. Eme R (2010) Male life-course-persistent antisocial behavior: the most important pediatric mental health problem. Arch Pediatr Adolesc Med 164: 486-487.

2. Moffitt T (1993) "Life-course-persistent" and "adolescent-limited" antisocial behavior. Psychological Review 100: 893-910.

3. Bushway S (2013) Life-course-persistent offenders. In: Cullen F, Wilcox P (eds.) Oxford handbook of criminological theory. New York, Oxford University Press.

4. Moffitt T (2006) Life-course-persistent versus adolescent-limited antisocial behavior. In: Cicchetti D, Cohen D (eds.) Development psychopathology. Hoboken NJ, Wiley.

5. Farrington D (2015) Prospective longitudinal research on the development of offending. Australian and New Zealand Journal of Criminology 48: 314-335.

6. Piquero A, Gonzalez J, Jennings W (2015) Developmental trajectories and antisocial behavior over the life-course. In: Morizot J, Kazemian L (eds.) The development of criminal and antisocial behavior. Switzerland, Springer International Publishing.

7. Chen FR, Jaffee SR (2015) The heterogeneity in the development of homotypic and heterotypic antisocial behavior. Journal of Development and Life Course Criminology 1: 269-288.

8. Moffitt TE, Arseneault L, Jaffee SR, Kim-Cohen J, Koenen KC, et al. (2008) Research review: DSM-V conduct disorder: research needs for an evidence base. J Child Psychol Psychiatry 49: 3-33.

9. Shaw DS, Hyde LW, Brennan LM (2012) Early predictors of boys' antisocial trajectories. Dev Psychopathol 24: 871-888.

10. Moffitt T, Caspi A, Rutter M, Silva P (2001) Sex differences in antisocial behaviour: Conduct disorder, delinquency, and violence in the Dunedin longitudinal study. UK, Cambridge University Press.

11. Moffitt TE (2005) The new look of behavioral genetics in developmental psychopathology: gene-environment interplay in antisocial behaviors. Psychol Bull 131: 533-554.

12. Beaver K (2013) The family concentration and transmission of crime. Criminal Justice and Behavior 40: 139-155.

13. Piquero A, Jennings W, Barnes W (2012) Violence in criminal careers: A review of the literature from a developmental life-course-perspective. Aggression and Violent Behavior 17: 171-179.

14. Vaughn M, Salas-Wright C, DeLisi M, Maynard B (2014) Violence and externalizing behavior among youth in the United States. Is there a severe $5 \%$ ? Youth Violence and Juvenile Justice 14: 3-21.

15. Farrington D, Loeber $R$ (2013) Two approaches to developmental life-course theorizing. In: Cullen F, Wilcox P (eds.) Oxford handbook of criminological theory. New York, Oxford University Press.

16. Fairchild G, van Goozen SH, Calder AJ, Goodyer IM (2013) Research review: evaluating and reformulating the developmental taxonomic theory of antisocial behaviour. J Child Psychol Psychiatry 54: 924-940.

17. Jennings WG, Reingle JM (2012). On the number and shape of developmental/ life-course violence, aggression, and delinquency trajectories: A state-of-the-art review. Journal of Criminal Justice, 40: 472-489.

18. LeBlanc M (2015) Developmental criminology: Thoughts on the past and insights for the future. In: Morizot J, Kazemian L (eds.) The development of criminal and antisocial behaviour. Switzerland, Springer International Publishing.

19. Shaw DS, Shelleby EC (2014) Early-starting conduct problems: intersection of conduct problems and poverty. Annu Rev Clin Psychol 10: 503-528.

20. DeLisi M, Piquero A (2011) New frontiers in criminal career research 2000 2011: A state-of-the-art review. Journal of Criminal Justice, 39: 289-301.

21. Assink M, van der Put CE, Hoeve M, de Vries SL, Stams GJ, et al. (2015) Risk factors for persistent delinquent behavior among juveniles: A meta-analytic review. Clin Psychol Rev 42: 47-61.

22. Hinshaw S (2013) Developmental psychopathology as a scientific discipline. In: Beauchaine TP, Hinshaw SP (eds.) Child and adolescent psychopathology. Hoboken, NJ, Wiley.

23. Raine A, Fung AL, Portnoy J, Choy O, Spring VL (2014) Low heart rate as a risk factor for child and adolescent proactive aggressive and impulsive psychopathic behavior. Aggress Behav 40: 290-299.

24. Choy O, Raine A, Portnoy J, Rudo-Hutt A, Gao Y et al. (2015) The mediating role of heart rate on the social adversity-antisocial behavior relationship: A social neurocriminology perspective. Journal of Research in Crime and Delinquency 52: 303-341.

25. Odgers CL, Caspi A, Broadbent JM, Dickson N, Hancox RJ, et al. (2007) Prediction of differential adult health burden by conduct problem subtypes in males. Arch Gen Psychiatry 64: 476-484.

26. Moffitt T (2006) Life-course-persistent versus adolescent-limited antisocial behavior. In: Cicchetti D, Cohen D (eds.) Development psychopathology 3: 570-598.

27. DeLisi M, Piquero A (2011) New frontiers in criminal career research 2000 2011: A state-of-the-art review. Journal of Criminal Justice 39: 289-301.

28. Alink L, Mesman J, Zeijl J, Stolk M, Koot H, et al. (2006) The early childhood aggression curve: Development of physical aggression in 10- to 50-month-old children. Child Development 77: 954-966.

29. Archer J (2004) Sex differences in aggression real-world settings: A metaanalytic review. Review of General Psychology 8: 291-322.

30. Archer J (2009) Does sexual selection explain human sex differences in aggression? Behav Brain Sci 32: 249-266.

31. Dodge K, Coie J, Lynam D (2006) Aggression and antisocial behavior in youth In: Eisenberg $\mathrm{N}$ (ed) Handbook of child psychology: Social, emotional and personality development 3: 719-785.

32. Tremblay RE (2010) Developmental origins of disruptive behavior problems the 'original sin' hypothesis, epigenetics and their consequences for prevention. The Journal of Child Psychology and Psychiatry 51: 341-367.

33. Tremblay R (2014) Early development of physical aggression and early risk factors for chronic physical aggression in humans. Curr Top Behav Neurosci 17: 315-327.

34. Card NA, Stucky BD, Sawalani GM, Little TD (2008) Direct and indirect aggression during childhood and adolescence: a meta-analytic review of gender differences, intercorrelations, and relations to maladjustment. Child Dev 79: 1185-1229.

35. Hyde J (2014) Gender similarities and differences. Annual Review of Psychology 65: $3.1-3.26$

36. Piquero A, Carriaga M, Diamond B, Kazemian L, Farrington D (2012) Stability in aggression revisited. Aggression and Violent Behavior 17: 365-372.

37. Romano E, Baillargeon RH, Wu HX, Zoccolillo M, Vitaro F, et al. (2004) A new look at inter-informant agreement on conduct disorder using a latent class approach Psychiatry Res 129: 75-89.

38. Farrington D (2007) Origins of violent behavior over the life span. In: Flannery $\mathrm{D}$, Vazsonyi A, Waldham I (eds.) Cambridge handbook of violent behavior and aggression, New York, Cambridge University Press.

39. Loeber R, Burke JD (2011) Developmental Pathways in Juvenile Externalizing and Internalizing Problems. J Res Adolesc 21: 34-46.

40. Pinker S (2011) The better angels of our nature: Why violence has declined. New York, Penguin Group. 
Citation: Eme R (2016) Radial Life-Course-Persistent Antisocial Behavior. J Foren Psy 1: 101. doi: 10.4172/2475-319X.1000101

Page 4 of 4

41. Buss D (2012) Evolutionary psychology: The new science of the mind. NewYork.

42. Tremblay RE (2006) Prevention of youth violence: why not start at the beginning? J Abnorm Child Psychol 34: 481-487.

43. Seguin JR, Tremblay RE (2013) Aggression and antisocial behavior: A developmental perspective. The Oxford Handbook of Developmental Psychology 2: 507-526.
44. Polanczyk GV (2015) Addressing the evidence gap on preventive interventions. J Am Acad Child Adolesc Psychiatry 54: 793-794.

45. McGee TR, Farrington DP, Homel R, Piquero AR (2015) Advancing knowledge about developmental and life-course criminology. Australian and New Zealand Journal of Criminology 48: 307-313. 